\title{
CHARACTERIZATION OF SINKHOLES AFFECTED AREA OF THULIBESHI PHAT, ARMALA, KASKI, NEPAL
}

\section{Moti Lal Rijal}

Journal of Institute of Science and Technology

Volume 22, Issue 1, July 2017

ISSN: 2469-9062 (print), 2467-9240 (e)

\section{Editors:}

Prof. Dr. Kumar Sapkota

Prof. Dr. Armila Rajbhandari

Assoc. Prof. Dr. Gopi Chandra Kaphle

JIST, 22 (1): 17-24 (2017)

Published by:

Institute of Science and Technology

Tribhuvan University

Kirtipur, Kathmandu, Nepal

Published by

Institute of Seience and Teehnology

Tribhuvan University

Kirtipur, Kathmanda, Nepal 


\title{
CHARACTERIZATION OF SINKHOLES AFFECTED AREA OF THULIBESHI PHAT, ARMALA, KASKI, NEPAL
}

\author{
Moti Lal Rijal \\ Central Department of Geology, Tribhuvan University, Kirtipur, Nepal \\ Corresponding E-mail: moti.rijal@gmail.com
}

\begin{abstract}
The area affected by sinkholes in Thulibeshi Phat of Armala VDC, Pokhara was studied in order to understand natural settings of the study area. A total of 117 sinkholes from depth range of 1 to $5 \mathrm{~m}$ and diameters from 1 to $15.2 \mathrm{~m}$ were observed at the time of our field visit. Out of these sinkholes, 52 sinkholes were filled sinkholes, 12 were water-bearing sinkholes and others were opened sinkholes. The area consists of sediments of fluvio-lacustrine and debris deposits and the sinkhole site has sediments mainly of silt, clay and fine sand size with chemical compositions of kaolin of major silica and minor constituents of calcium carbonate. The main mechanism of formation of sinkholes in Thulibeshi Phat was washed-away effect generated by piping mechanism of fine sediments by sub-surface flowing water, which was initiated by partial dissolution of carbonate containing sediments. Human impact on landscape, especially land use changes and stream channel modifications accelerated the process of piping mechanism for initiating and extending the sinkhole affected area in the present study site. This study will help to understand how geological conditions and human impacts interact to form sinkhole hazards in Nepal.
\end{abstract}

Keywords: Sinkhole, Land subsidence, Armala, Piping mechanism, Human impact.

\section{INTRODUCTION}

Earth is a dynamic planet and earth processes are happening all the times since origin of the earth. Earth's mass movements happens under the gravitational force and mass movements are classified into different frames by different authors who have worked in areas of mass movements of earth's materials from upslope to down slope. Mass movements of earth's surface were classified into two categories by Varnes (1978) depending on types of materials and types of movements. Generally, earth's surface modifications by transportation and depositional geological agents are also grouped broadly into two types as aggradation and degradational processes, which brings level up and level down to the previously formed earth's surface respectively.

Land subsidence is the motion of the earth's surface downwards relative to its datum. Subsidence is the major geologic features of karst terrains, where dissolution of rock or sediment by fluid flow in the subsurface causes the creation of voids. These specially occur in carbonate rocks, and may have a variety of sizes and are morphologically expressed as a function of its evolution mechanisms. In the present world, sinkholes (SH) are among the most significant geo-hazards of karsts areas of various countries, with significant negative consequences for society in terms of economic losses (Galloway \& Sneed, 2013).

Subsidence, based on the morphology of the failure and the triggering agent, may be termed as Sinkhole or ground subsidence, though these two are entirely different on morphology and process of their evolution. In the last few years, the term sinkhole has been used often to indicate collapse phenomena of different natures. Such a term defines a subcircular surface depression or collapse structure formed by the collapse of small subterranean karst cavities.

At present, the term sinkhole is frequently used to define any sub-circular cavity regardless of its genetic origin. The term is also used to indicate open cavities caused by anthropogenic activities, that are not necessarily sub-circular in form (Nisio et al., 2007). Sudden collapses are also defined as those events that are not directly linked to karst phenomena; such as subterranean cavities formed by anthropogenic activities in urban areas, above mines, excavations and ancient catacombs.

In the geophysical investigations of Pokhara quaternary sediments by Gautam et al. (2000) 
showed positive anomalies around the cave area representing the krastic features in the subsurface and mentioned that the sub-surface karsts and subsurface channel may induce land subsidence in the future. Abelson and Gabay (2009) came out with the conclusions of their studies that under-saturated water accessed the salt layer via faults that cut through the soft aquiclude layers as the primary causes of sinkhole formation. In addition, the essential factors of all sinkhole development are the dissolving of the underlying limestone/sediments by slightly acidic water was also mentioned by Tihansky (1999). He described the phenomena of dissolution of calcareous components especially along the fractures and weak layers by acidic water and creating the chemical erosion eventually causes voids or cavities into which overlying sediments may collapse or subside. The result of chemical erosion followed by physical collapse or subsidence is a sinkhole.

Due to anthropogenic causes of formation of sinkholes and land subsidence, such as excessive use of groundwater for irrigation has resulted in land subsidence as studied by Chan (1994). Subsurface flow can be rapid when coupled with rapid recharge. With respect to the rapid recharge, exchange of ions between groundwater and subsurface water increases as groundwater is under saturated with respect to soluble subsurface minerals. This inequillibrium ultimately leads to dissolution of subsurface sediments. Such dissolution ultimately leads to more subsidence in the area (Sasowsky \& Wicks, 2000).

The occurrence of sinkhole in the Himalayas was first reported in the Runjh village in Himalchal Prades, India in 1970, which was situated in Precambrian basic volcanic rocks. The subsidence was caused due to the solvent action of subsurface water on salt, which occur on the sub-thrust side of the basic volcanic nappe with the consequent removal of the support that ultimately affect the roof to sustain the lithostatic load, leading to the formation of catastrophic cylindrical type sinkhole (Srikantia \& Bhargava, 1972).

This study basically focus on the characterization of subsidence sites and dimensions of land subsidence of Thulibeshi Phat of Armala VDC. The main objective of the present study was to characterize sinkhole area of Thulibeshi Phat in Armala VDC, with specific objectives to understand geological settings of the sinkhole affected sites and its surroundings, categorization of sediments inside sinkholes and assess the current land use and historical information of the sinkhole affected area. This will help us to understand the process of sinkhole formation, their temporal and spatial development and potential expansion area of sinkhole.

\section{MATERIALS AND METHODS}

\section{Study area}

Thulibesi Phant lies in Armala VDC of Kaski district. It lies in north near to the Mahendra cave of Pokhara Valley. Population size is 5,328 with 1,336 households in Armala VDC (CBS 2011). Geologically the area falls under the quaternary deposit sediments. The area is characterized by the succession of former lake sediments and fluvial sediments and is a part of the present day flood plain of Kali Khola. Armala VDC is situated in the North part of Pokhara and is accessible by motor able road. The place is about $240 \mathrm{~km}$ from Kathmandu via Prithvi Highway. The study area is shown in figure 1 . The areas affected by sinkholes are also clearly visible in figure 2 inside the solid line.

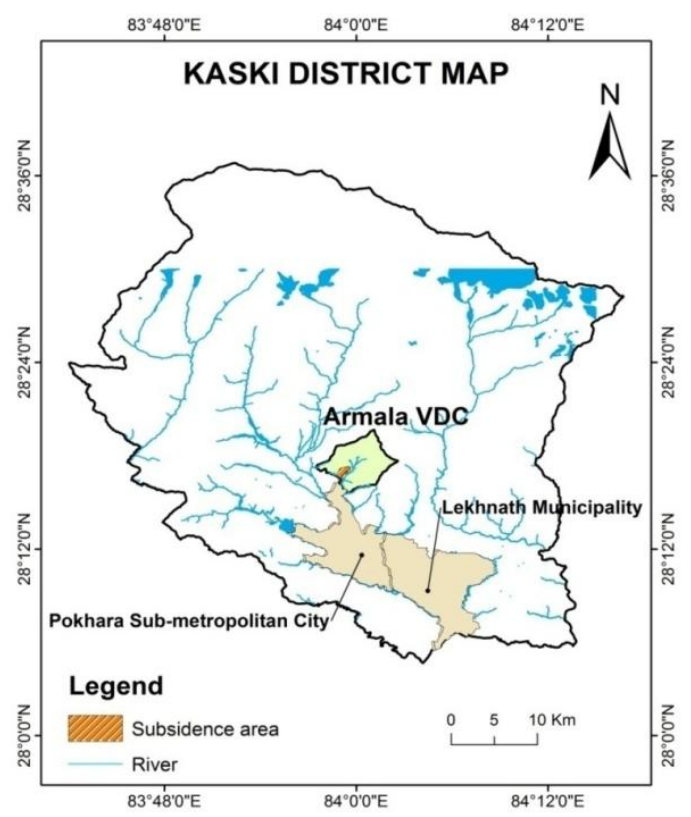

Fig. 1. Location map of the study area showing Armala VDC and subsidence area with bordering Lekhnath Municipality and Pokhara Submetropolitan City.

The climate of the area is sub-tropical with summer temperatures ranges between 25 to $35^{\circ} \mathrm{C}$ and winter temperature between -2 to $15^{\circ} \mathrm{C}$. Pokhara and nearby areas receive highest precipitation in the country. 


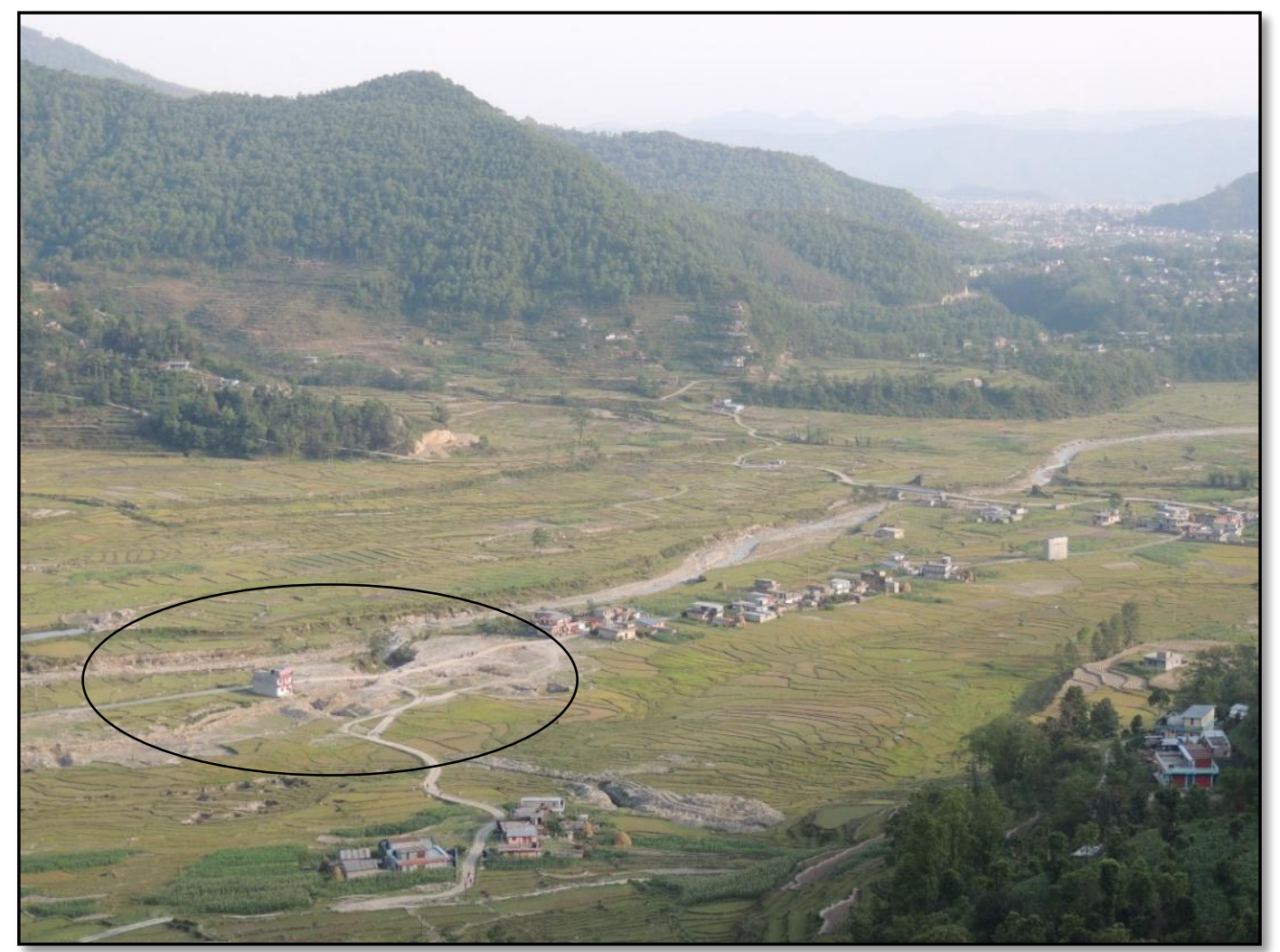

Fig. 2. An overview of study area and distributions of sinkholes in the area as encircled by an oval shaped solid line.

\section{Field study}

In order to conduct a systematic study of sinkhole affected area and its surroundings, a one week field work was conducted during the month of May in 2014.

\section{Locating Subsidence Sites and mapping of lithological sections}

The field work mainly consists of the transect walk and observation around the study area. The subsidence site was located with the help of the GPS. The dimensions of open and filled sinkholes were measured using measuring tape and the sediment profile of open sinkholes were recorded and a systematic sediment profiles were divided into different categories by direct measurement and observations of sediment types and their thicknesses.

\section{Analysis of Google Earth image}

The Google Earth Images of different time period from the sinkhole affected area were viewed using open Google Earth Image and the image of 2014 was extracted from it and was redrawn using Q-GIS for the preparation of land use map of the sinkhole affected area.

\section{RESULTS}

\section{Geology}

Pokhara valley is an intermontane valley. Geological histories revealed Pokhara valley to be a clusters of paleo lakes (DMG, 1997 and 1998). Sediments were derived from around the surrounding hill with two major huge debris flows events (Yamanaka et al., 1982). Several geological investigations around the Pokhara valley, have reported Armala valley as a part of the clusters of small lakes that comprised ancient Pokhara valley. Huge masses of debris flow from around the Annapurna Areas, during different periods had been deposited in these lakes. Thus, the sediment mainly comprise of well sorted gravel, boulders, sand, silt, and fine silt and clays from the lacustrine environment. The sediments are fluviolacustrine origin.

According to the Engineering and Environmental Geological map of Pokhara Valley (DMG, 1998), the Pokhara valley represents an intermontane fluvial basin spread around the midstream of the Seti River, in the Lesser Himalaya of Nepal. It is filled by large volume of layered clastic deposits 
(gravel, silt and clay) of quaternary age, brought from the Annapurna mountain range probably by a series of catastrophic debris flows (Yamanaka et al., 1982). Due to the presence of easily soluble calcareous material $(25-65 \%)$ by volume in the clastic sediments, splendid river terraces and deep gorges are carved by the Seti River and its tributaries. Karst structures (subsurface flow channels), solution cavities, $\mathrm{SH}$, pinnacles, solution chimneys, etc. are widely developed both at the surface and underground. This area was already indicated the area prone to subsidence by the reports of DMG (1998).

\section{Topography and drainage}

The lowest altitude in the study area is $962 \mathrm{~m}$ and the highest altitude is $1144 \mathrm{~m}$. The drainage pattern of this area is dendrite type. Lowland and highland settlements have distinct differences in biodiversity and socio-economic conditions of the people. The study area is surrounded by hills which get recharged by springs and rivers which lie nearby shown in figure $3 \mathrm{a}$.
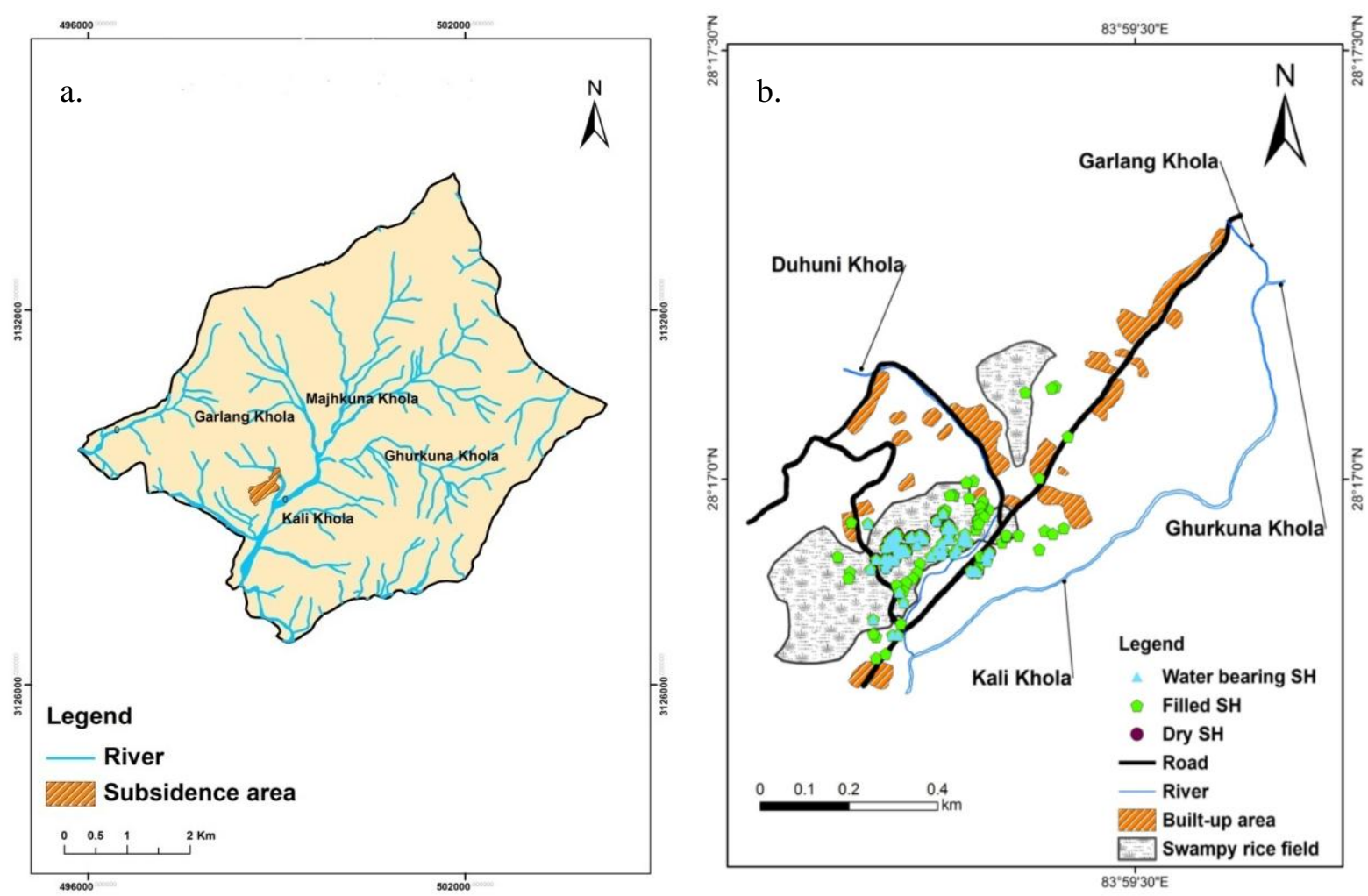

Fig. 3(a). Drainage map of Sinkhole affected area with Majkhuna Khola, Garlang Khola, Ghurkuna Khola and Kali Khola. (b) Sinkhole Categorization into three different types: water bearing SH, filled SH and dry sinkholes SH. This map also shows land use patterns surroundings of sinkholes affected area in 2014.

\section{Subsidence site and sinkhole categorization}

Subsidence site covered around 1200 hectares of the area. Sinkholes with different morphology and sizes were identified and categorized. A total of $117 \mathrm{SH}$ were observed, $24 \mathrm{SH}$ containing water or water seepage, $52 \mathrm{SH}$ were totally filled with the gravel, sand and 41 SH were dry with deposited sediments at the base due to collapsed of their sidewalls. Sinkhole categorization is shown in figure $3 b$.
The maximum and minimum diameters were $15.2 \mathrm{~m}$ and $1 \mathrm{~m}$ respectively in the study area. The number of $\mathrm{SH}$ with different diameter range is shown in figure 4 . The $\mathrm{SH}$ formed with circular pattern were considered and $14 \mathrm{SH}$ which were formed with longitudinal pattern was neglected during the study. Among the SH, 32 were observed with diameter less than 5m, 17 were identified with diameter 5$10 \mathrm{~m}$, one $\mathrm{SH}$ each having diameter between 10$15 \mathrm{~m}$ and more than $15 \mathrm{~m}$. Similarly, $52 \mathrm{SH}$ were found filled sinkholes during the time of study. 


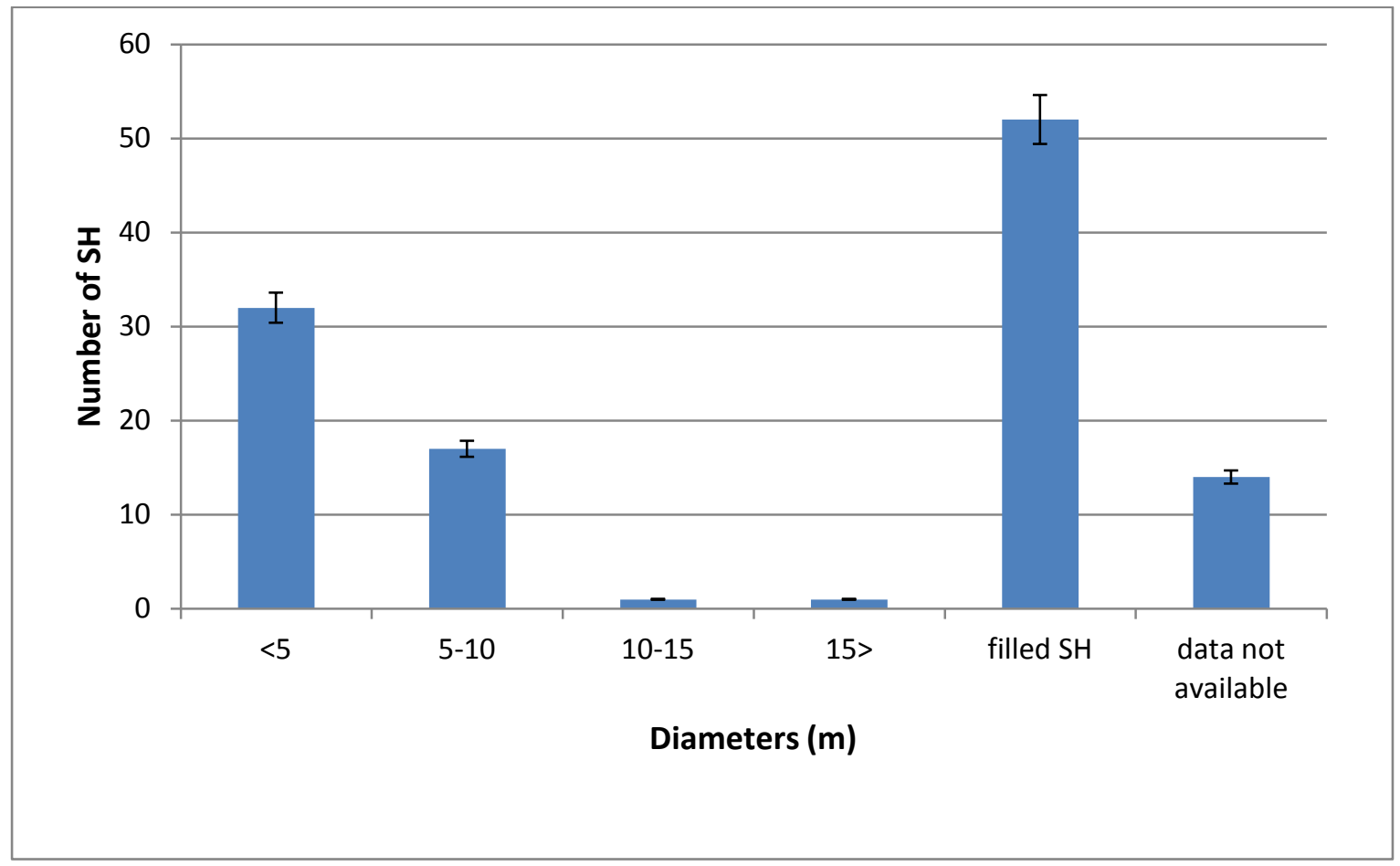

Fig.4. Sinkholes diameter distribution in the study area.

$\mathrm{SH}$ in the area were usually found in the depth range of $1 \mathrm{~m}$ to $5.5 \mathrm{~m}$. The maximum and minimum depth of the SH was found to be $5.7 \mathrm{~m}$ and $0.9 \mathrm{~m}$ respectively. SH containing water in them was neglected while taking the depth of the SH. Figure 5 indicates the depth of SH. Among them, $19 \mathrm{SH}$ have depth between 1-2m, $16 \mathrm{SH}$ have depth of 2$3 \mathrm{~m}$ and few having depth greater than $5 \mathrm{~m}$.

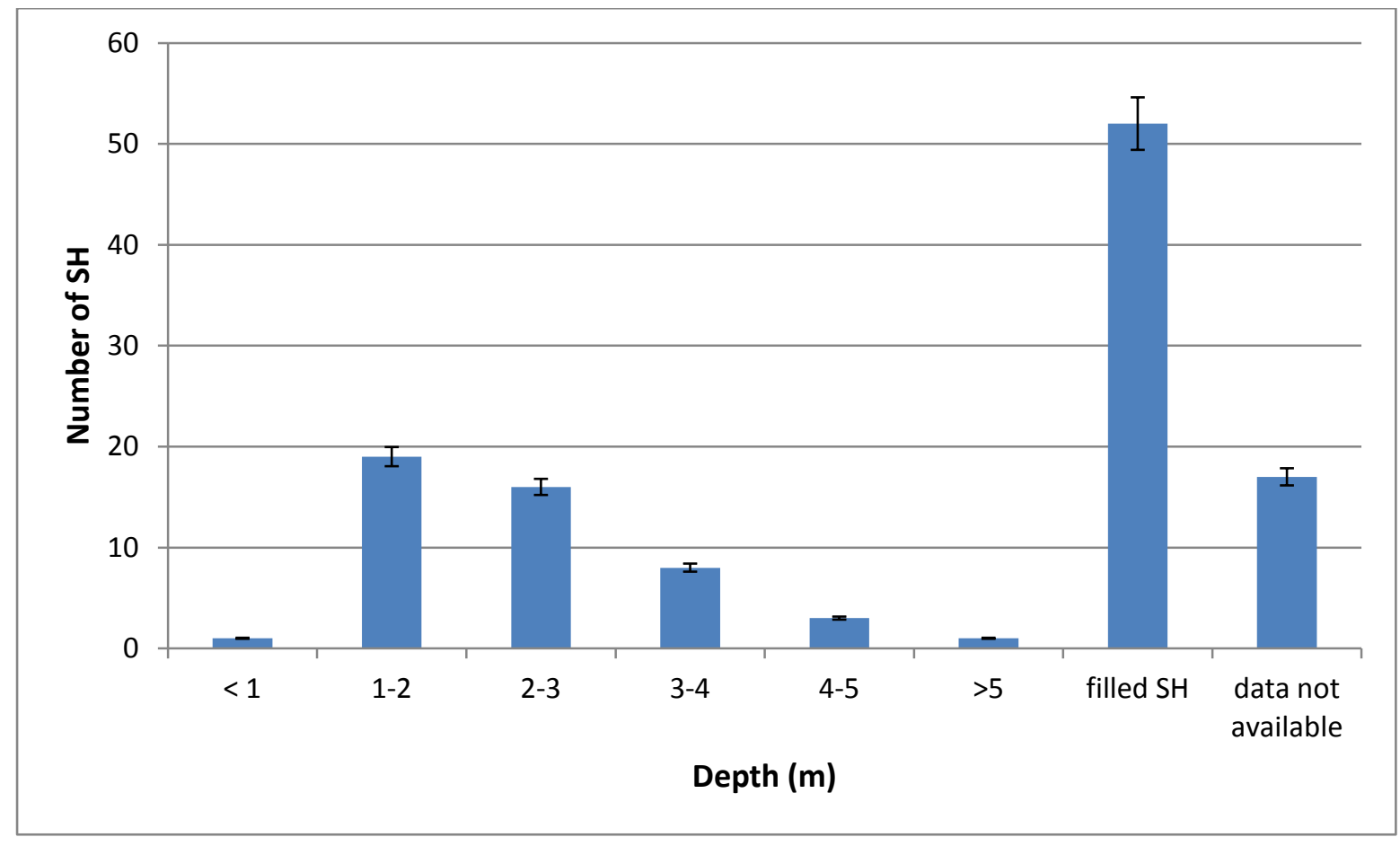

Fig.5. Sinkholes depth distribution in the study area. 


\section{Mapping Sediment profiles of sinkholes}

Many of the sinkholes nearby settlements were already filled by carrying boulders gravels and sands from the nearby riverbeds because of its potential hazards for humans, mainly small children and domestic animals. However, some of the sinkholes still remain in opened conditions and these sinkholes of natural conditions were easily visible from outside. Some sinkholes were even possible to gain entrance because side walls have collapsed and were in stable side-wall conditions. Therefore, it was a good chance to map and categorize sediments profiles of all sinkholes of which sediments were visible. The representative sediments profiles of different categorized of sediments were presented below.

As revealed from direct field observations of various sinkholes, $\mathrm{SH}$ in the area have two distinct types of sediment profiles. One group of $\mathrm{SH}$ comprised of a sediment profile with 4 distinct layers; the uppermost layer, $70 \mathrm{~cm}$ thick, consist of pebbly gravel with silty clay cementing matrix, followed by a $10 \mathrm{~cm}$ thick layer of oxidized gravel, $120 \mathrm{~cm}$ thick layer of silty clay with sand and the lower most layer, the black clay layer, with a thickness of more than $100 \mathrm{~cm}$. Some of these $\mathrm{SH}$ contain water seepage from gravel and silty clay. Figure 6 describes a generalized sediment profile of the sinkhole in the study area.

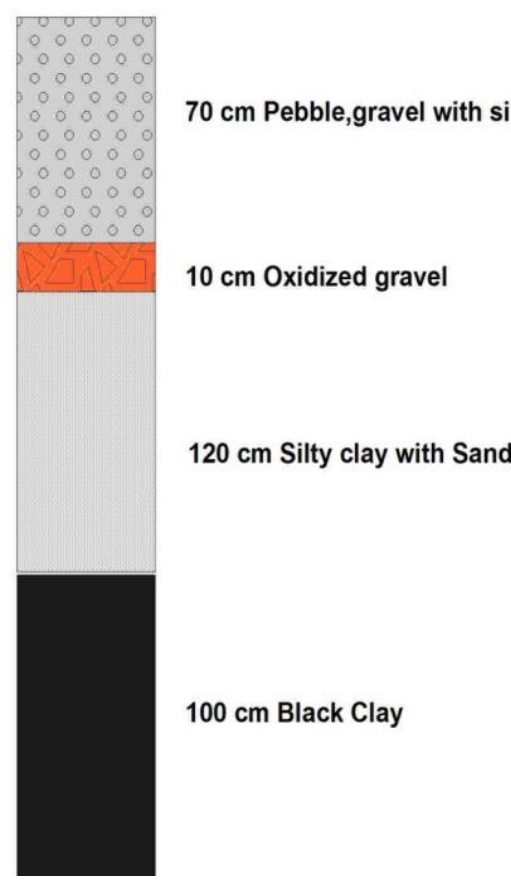

Fig.6. A generalized sediment profile of the study area.
Whereas, the second type of sediment profile have 5 distinct layers. The uppermost layer of silty-sand about $60 \mathrm{~cm}$ thick with occasional clay layer was followed by a $30 \mathrm{~cm}$ grayish gravel layer. An oxidized layer of about $70 \mathrm{~cm}$ thick was observed below this gravel layer. The bottommost layer of $200 \mathrm{~cm}$ grayish gravel was underlined a white silty clay layer at the base.

\section{Land use pattern}

Most of the study area was built from the alluvial terrace of Kali Khola and was widely used as agricultural land. Human settlements are around the right bank of Kali Khola and in nearby hill spurs. The development of the settlement area has been increased during recent years (Fig. 3b).

The land use pattern has undergone drastic changes during last several years as mentioned by villagers and also revealed by Google Earth Images of several years. The area was primarily occupied by a swampy land in the lower part and most of the area was used for rice farming land till 2004, which is now covered by settlements, new road networks. Houses and school buildings are located alongside the road network nearby the bank of Kali Khola. Duhuni Khola, which primarily ran perpendicular to the swampy rice field, has now been encroached by the black topped road. The former river bed of Kali Khola was lowered due to continue extraction of construction materials and its river bed is significantly lowered nowadays by the river bed around the Kali Khola Bridge.

\section{DISCUSSION}

Land subsidence or Sinkholes are types of degradation processes of earth's pre-existing surface. The term sinkhole derives from the processes of its evolution either by sinking of ground surface forming a closed depression by washed-away process of underlying sediments due to sub-surface flowing water. These physical types of washed-away process is some time also enhanced by a slow process of chemical dissolution of its soluble rock or previously deposited carbonaceous sediments and a ground may subside catastrophically in a collapse event. Sometimes, a stream sinks into sinkholes. Such discrete sink points are better known as sinks, stream sinks, swallow holes, and such sinkholes may or may not be within the floor of a sinkhole depression (Waltham et al., 2005).

In the present study area, sinkholes were primarily dry and water bearing sinkhole which were 
normally formed in longitudinal pattern along the Duhuni Khola. The circular structures of this subsidence readily depict a sediment profile showing both the fluvial sediments of gravel \& sand and that of lakes with kaolin \& fine silts. The morphology of the SH varies from one another and formed a circular cylindrical structure. Based on the genetic processes, collapse phenomena can be subdivide into anthropogenic sinkhole, karst phenomena and deep piping sinkhole. It has been noted that the majority of the $\mathrm{SH}$ are a result of upward erosion. Deep piping phenomena is mainly responsible for originating of sinkholes in this area as described by Nisio et al. (2007). They also highlighted the causes of anthropogenic activities which quickly develop in terrain with variable sediment layers in connection with upwelling fluid which defines the relationship between geology and genesis of the sink holes. Whereas, the transportation of sediments due to flowing underground water leads to formation of an underground hollow structure is also mentioned by Waltham et al. (2005).

The chemistry of sediments from the geological strata, deposited in the sinkholes and suspended in water indicate a similar value for $\mathrm{SiO}_{2}, \mathrm{Fe}_{2} \mathrm{O}_{3}, \mathrm{CaO}$ and $\mathrm{MgO}$. This similarity in the sediment analysis indicates the physical process of transportation is more dominant in the area rather than the chemical dissolutions processes. This clearly showed that the piping mechanism is mainly responsible for washed-away process of originally deposited sediments in this area. According to the Armala Land Subsidence Inventory Report (MoHA, 2014), weak geological conditions, easily washable sediments like calcareous silt and clayey silt is a major factor in sinkhole formation.

The change in land use pattern, over last several decades decade, in the study area, indicated the encroachment of the Duhuni Khola. The increment of settlement and human activities in the area significantly reduced the flow channel of Duhuni. The subsurface flow of ground water is readily a natural process. However, the pressure movement of subsurface ground water increases the turbulence. Thus prompting a linear pressure flow this ultimately develops piping mechanism.

The current land use pattern of this study area is also different than the land use of last several years, which was also informed by the local inhabitants of this area. The area, which was mostly agricultural land, dominated by rice fields and swamy area is now converted into settlements and built-up areas. Not only this, the original stream channels of many tributaries of Khali Khola originating from the study area were either buried or their pathways were modified. Kali Khola river bed is lowered by several meters due to mining of river-bed materials that were used for building and road constructions of mainly Pokhara Sub-metropolitan city.

In case of Armala, the washing away of the silty clay with the flow of sub-surface water has been clearly observed during the field study of the area indicating the piping mechanism of forming sinkholes. It shows that sinkhole develops with the slow washing away of the sediments from the base to the top of the cavity. The fissures which were seen during the field visit in the channel of the Duhuni Khola indicates the entering of the water below ground, which makes its path through the sub-surface flow and the outlet to Kali Khola. The worldwide phenomena of formation of sinkholes in karst topography with the major process of chemic of dissolution of the carbonate rock creating void first and then followed by collapsed of earth's surface materials do not corresponds with the processes of formation of sinkholes in the present study area of Thulibeshi Phat of Armala. Whereas, in the current study site, the washed-away process of removal of sediments of mostly silty and fine sandy sized by sub-surface water is the dominant process before forming collapse structures. So, it's a different form of subsidence structure and genetically different that commonly formed sinkholes of karst terrain.

\section{CONCLUSION}

The geological settings of the area, which is dominated by fluvio-lacustrine sediments of silt and fine sands sized particles along with land use changes over past several decades, are the primary reason of sinkhole formation in the area. The sinkhole development is a direct consequence of piping mechanism. The piping mechanism is best described by the changes in mineralization of water, flowing immediately before and after the sinkhole. The initiation of piping mechanism has been thoroughly supported by physical and chemical nature of sediments previously deposited by fluvial, lacustrine and debris processes.

A thorough investigation of water sources, especially springs that are feeding streams draining into sinkholes affected site are required to trace the pathways of water flowing into the sinkhole site. 


\section{ACKNOWLEDGEMENTS}

I would like to thank N. Lamichhane, who has helped during the field work at the Thulibeshi Phat. U. Bhusal is highly acknowledged for arranging financial support during the field work. Many local residents of the area, who provided me valuable information about historical information on land use systems of the sinkhole affected area, sinkholes formation and their development are highly appreciated. Additionally, the comments of an anonymous reviewer and the chief editor to improve the previous version of this manuscript are also highly acknowledged.

\section{REFERENCES}

Abelson, M. and Gabay, R. (2009). Sinkholes hazard around the evaporation ponds Dead Sea southern basin, GSI, 27, Ministry of National Infrastructures Geological Survey of Israel.

CBS, (2011). National Population and Housing Census 2011 (Village Development Committee/Municipality).

Chan, Y. C. (1994a). Factors Affecting Sinkhole Formation, Geotechnical Engineering Office, Hong Kong, GEO Report 28, pp. 46.

DMG, (1997). Engineering and Environmental Geological map of Pokhara Valley.

DMG, (1998). Engineering Geological Report of Pokhara Valley.

Galloway, D. L. and Sneed, M. (2013). Analysis and simulation of regional subsidence accompanying groundwater abstraction and compaction of susceptible aquifer systems in the USA. Boletín de la Sociedad Geológica Mexicana, 65: 123-134.

Gautam, P.; Pant, S. R. and Ando, H. (2000). Mapping of subsurface karst structure with gamma ray and electrical resistivity profiles: a case study from Pokhara valley, Central Nepal. Journal of Applied Geophysics, 45: 97-110.

MoHA, (2014). Armala Land Subsidence Inventory Report.

Nisio, S.; Caramanna, G. and Ciotoli, G. (2007). In: M. Parise , J. Gunn (eds) Sinkholes hazard in Italy: first results on the inventory and analysis of some case studies. Geological Society London Special publications: Natural and anthropogenic hazards in karst: Recognition, Analysis and Mitigation, 279: $23-45$.

Sasowsky, I. D. and Wicks, C. M. (2000). Groundwater flow and contaminant transport in carbonate aquifers, Taylor \& Francis, UK, pp. 203.

Srikantia, S. and Bhargava, O. (1972). Subsidence Sinkhole at Runjh (Himachal Pradesh, India), Engineering Geology, 6 (3): 191-201.

Tihansky, A. B. (1999). Sinkholes, West-central Florida. Land Subsidence in the United States. United States Geological Survey Circular, 1182: 121-140.

Varnes, D. J. (1978). Slope movement types and processes. In: RL Schuster and RJ Krizek (eds) Special Report 176: Landslides: Analysis and Control. Transportation and Road Research Board, National Academy of Science, Washington D. C., 11-33.

Waltham, T.; Bell, F. and Culshaw, M. (2005). Sinkholes and subsidence. Karst and cavernous rocks in engineering and construction, Springer, Chichester, pp. 382.

Yamanaka, H.; Yoshida, M. and Arita, K. (1982). Terrace landform and Quaternary deposits around Pokhara valley, Central Nepal. Nepal Geological Society, 2: 95-112. 